\title{
Frequency reconfigurable antennas for cognitive radio applications: a review
}

\author{
Ros Marie C. Cleetus, G. Josemin Bala \\ Department of Electronics \& Communication Engineering, Karunya Institute of Technology and Sciences, India
}

\begin{tabular}{|c|c|}
\hline Article Info & ABSTRACT \\
\hline & \multirow{11}{*}{$\begin{array}{l}\text { Wireless communication systems undergo tremendous growth these days and } \\
\text { devices able to operate in a number of frequency bands are highly demanded. } \\
\text { Reconfiguration in antenna characteristics triggered the evolution of antennas } \\
\text { that can work in multiple frequency, pattern or polarization environment. The } \\
\text { frequency reconfigurable antennas thus emerged are well suited in Cognitive } \\
\text { Radios which take part in the effective utilization of unused bands of } \\
\text { frequencies by continuously interacting with the RF environment. Thus, } \\
\text { Cognitive Radios enhance the utilization of frequency spectrum and establish } \\
\text { reliable communication. The most recent research works carried out in the } \\
\text { arena of Frequency Reconfigurable Antennas for Cognitive Radio } \\
\text { applications are reviewed and summed up in this paper to present the } \\
\text { attributes and categorization. Four techniques adopted to attain frequency } \\
\text { reconfiguration are extensively compared in this paper to find the advantages } \\
\text { and constraints of each methodology. The applications of the works reviewed } \\
\text { here are not only limited to Cognitive radios, but extended to a number of } \\
\text { wireless communication services like, WLAN, WiMAX, etc. }\end{array}$} \\
\hline Received Jul 25, 2018 & \\
\hline Revised Apr 4, 2019 & \\
\hline Accepted Apr 14, 2019 & \\
\hline & \\
\hline Keywords: & \\
\hline Bandwidth & \\
\hline Cognitive radio & \\
\hline Microstrip patch antenna & \\
\hline Reconfigurable antenna & \\
\hline Ultrawideband antenna & \\
\hline
\end{tabular}

Copyright (C) 2019 Institute of Advanced Engineering and Science. All rights reserved.

\section{Corresponding Author:}

Ros Marie C. Cleetus,

Department of Electronics \& Communication Engineering,

Karunya Institute of Technology and Sciences,

Karunya Nagar, Coimbatore, 641114, Tamilnadu, India.

Email: ros_bina@yahoo.in

\section{INTRODUCTION}

Telecommunication, the day-by-day growing segment of communication industry is fully dependant on Radio waves and Radio Frequency spectrum (RF Spectrum) coordinated by certain regulations defined by the International Telecommunication Union (ITU). The ITU has divided RF spectrum to a number of frequency bands and has allotted the bands to various wireless services like 3G, LTE, WLAN, Wi-Fi, GSM, Bluetooth, etc.

The recent advancement of communication technologies and the increased demand of bands of frequencies triggered a paucity in the available RF spectrum. The reason to this shortfall is amateurish management policies of spectrum allocation than the lack of usable frequencies [1]. According to The Federal Communications Commission (FCC, 2002), most of the spectrum is not effectively utilized [2]. It could be seen that $70 \%$ of the allotted licensed spectrum stands to be unexploited [3]. Hence, it is the necessity of current era that this situation is to be avoided by ensuring efficient usage of licensed spectrum in such a way that unused frequency bands must be detected and shared to users without interferences.

In one word, the solution to this problem is Cognitive Radios (CRs), which can act as smart communication systems by learning from and adapting to the surroundings. The Cognitive Radio is structured with a sensing antenna, mostly an ultra wide band antenna that steadily scans the spectrum for the bands left unused and a reconfigurable antenna to communicate with those unused bands [4]. Thus, CRs establish a dependable communication scheme by effectively exploring the underutilized or unoccupied 
frequency bands that leads to efficient spectrum usage [5]. The highest efficiency in spectrum usage is promised by frequency reconfigurable antennas. Such reconfigurable antennas reject interference from coexisting standards or services and avoid the usage of filters. When multi band systems are used, the cost and volume of the systems will be reduced whereas the versatility will be increased [6]. The frequency reconfigurable antennas used in CRs are desired to possess better frequency selectivity, high gain and isolation, wide tuning range and consistent pattern [7, 8]. As the magnitude of the Frequency Reconfigurable antennas for Cognitive Radio Applications is expanding progressively, in this paper, the latest developments occurred in this area are surveyed and summarized. Hence, presented the reconfiguration techniques for frequency reconfigurable antennas in Cognitive Radio systems and the comparison of various techniques in Results and Discussion, followed by the Conclusion.

\section{RECONFIGURATION TECHNIQUES FOR FREQUENCY RECONFIGURABLE ANTENNAS}

Four distinct methods are there to achieve Frequency Reconfiguration in antennas. First method to achieve frequency reconfiguration is Electrical in which antennas are reconfigured using Radio FrequencyMicroelectromechanical systems (RF- MEMS) [9-14], PIN diodes [15-18], or varactors [19-21]. Second method is Optical where such antennas use photoconductive switches to achieve reconfiguration [22-26]. Third method is to provide structural alteration to the antenna to attain reconfiguration which are called physically reconfigurable antennas [27-32]. The last method is to use, smart materials for achieving reconfiguration [33].

\subsection{Electrically reconfigurable antennas}

Electrical reconfiguration is achieved via switching components such as RF-MEMS, PIN diodes, or varactors. These components will be acting as switches and directing surface currents in order to change the antenna radiator topology. Switches can be easily integrated into the antenna and these exhibit good isolation and minimal losses. The disadvantages of this method include the non- linear nature of switches, requirement of biasing lines to control the switching states, losses associated, added complexity, etc.

\subsubsection{Reconfigurable antennas for cognitive radios based on RF-MEMS}

It reports a reconfigurable antenna using RF MEMS switch for cognitive radio applications in [9]. It describes a reconfigurable monopole UWB antenna with single notched feature achieved by an octagonal shape patch and RF MEMS switch. The notched band could be obtained by etching the meandered slot in the patch. And the effect of the slot is minimized by an RF MEMS switch in the center of the meandered slot. The design of the antenna and the simulated return loss are shown in Figure 1. If the switch is in the ON-state, the antenna operates as an UWB antenna working in the frequency range $3.2 \mathrm{GHz}$ to $12 \mathrm{GHz}$. If the switch is in the OFF-state, a single notch can be found from $3.3 \mathrm{GHz}$ to $4.1 \mathrm{GHz}$.

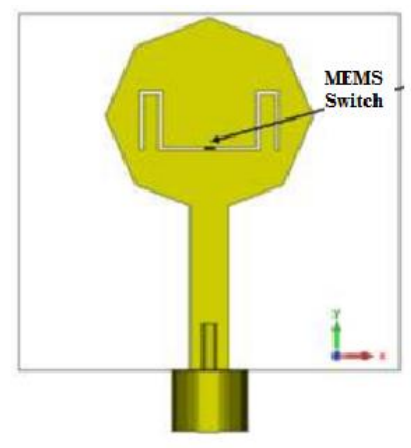

(a)

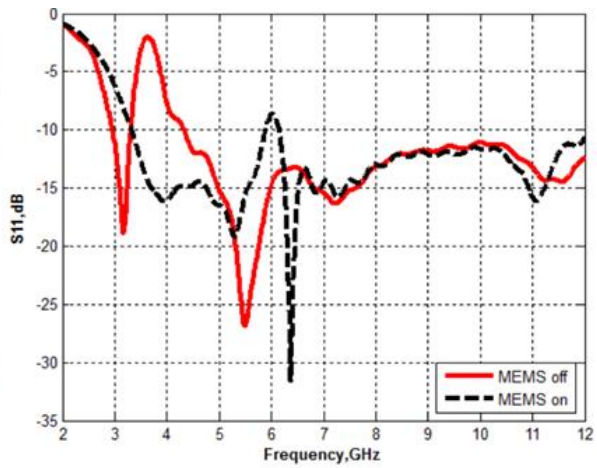

(b)

Figure 1. (a) The design of the antenna, (b) Simulated return loss at different switching states

Another MEMS reconfigurable combined circular and rectangular shaped slotted microstrip patch antenna for cognitive radio applications is presented [10]. It is designed to operate within 2 to $5 \mathrm{GHz}$. MEMS switches are used for fast switching and better adaptation. The switching operation is accomplished using Particle swarm optimization and nature inspired optimization techniques. Slots are incorporated into the antenna to enhance the return loss in order to reduce the mismatch between transmission line and antenna. 


\subsubsection{Reconfigurable antennas for cognitive radios based on PIN diodes}

A meandered reconfigurable F-shaped antenna is presented in [15]. It is a 4 element, multiple input multiple output (MIMO) antenna system that works in dual mode. Frequency agility is obtained using PIN diodes whereas frequency tuning is acquired by varactor diodes. To reduce the mutual coupling between different MIMO elements, an isolation enhancement technique is introduced. To eliminate the mutual coupling between horizontal antenna elements, defected ground slots are applied whereas to improve the isolation between vertical antenna elements, staircase type ground plane structure is employed. Two modes of operations according to the switching states of PIN diodes is obtained. The first mode, when the PIN diode switches are in OFF state and varactor diodes are reverse biased, the frequency bands covered are found to be 1170 and $2420 \mathrm{MHz}$ with almost $100 \mathrm{MHz}$ bandwidth in both the bands. The prototype of the antenna and the simulated and measured reflection coefficients of the first mode are shown in Figure 2. In the second mode, when the switches are $\mathrm{ON}$, and reverse bias applied to varactor diode is varied in between $0 \mathrm{~V}$ and 6 $\mathrm{V}$, and resonating frequencies are found to be varied between 743 and $1030 \mathrm{MHz}$, and $2400 \mathrm{MHz}$. The bandwidths for these two bands are $60 \mathrm{MHz}$ and $120 \mathrm{MHz}$.

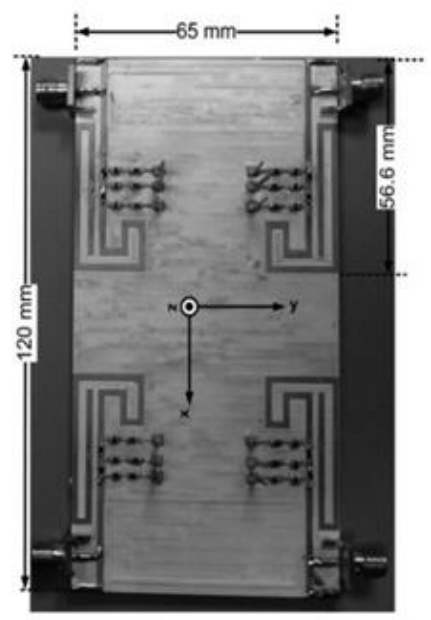

(a)

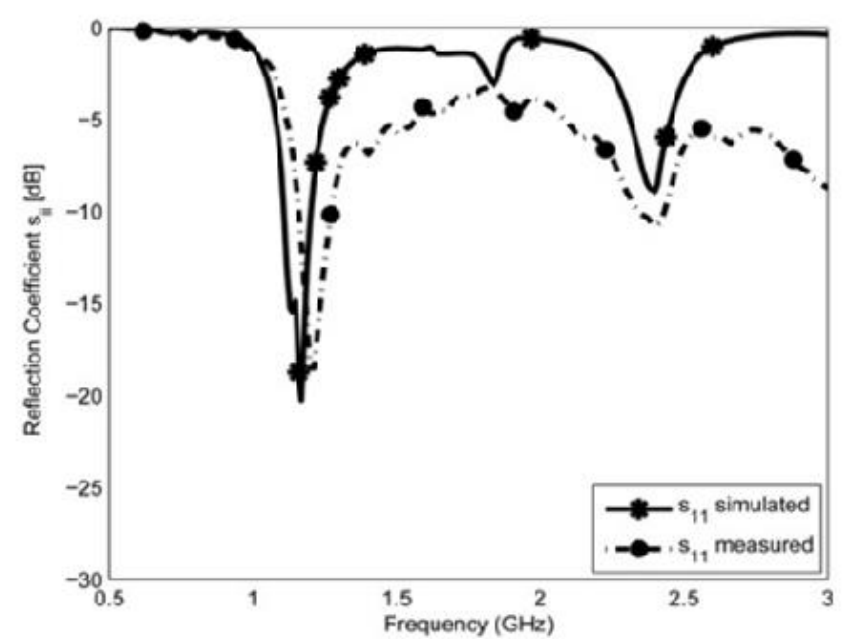

(b)

Figure 2. (a) Fabricated Model, (b) Reflection coefficients at first mode of operation

Another microstrip circular monopole antenna with a reconfigurable 10-dB impedance bandwidth for cognitive radios is reported in [16]. It is fed by a microstrip line integrated with a bandpass filter based on a three-line coupled resonator. The reconfiguration of the filter allows the antenna to operate at either in wideband or in narrowband by a PIN diode. Tuning is done from 3.9 to $4.82 \mathrm{GHz}$ for the narrowband.

\subsubsection{Reconfigurable antennas for cognitive radios based on varactors}

A frequency reconfigurable as well as compact filtenna with a keen out of band rejection in sensing and communicating states for cognitive radio applications is reported in [19]. To switch the filtenna between sensing and communicating states, employed a PIN diode in the design. In the communicating state, two varactors are introduced in the $\mathrm{C}$ shaped resonator for the frequency shifting from $3.05 \mathrm{GHz}$ to 4.39 $\mathrm{GHz}$. The filtenna exhibits exclusive out of band rejection nature at sensing stage. The operation is switched between two states: wideband and narrow band. It is done by switching the PIN to OFF and ON states respectively. When the filtenna is in narrow band state, the operational frequencies can be continuously shifted by tuning the bias voltage given to the varactors. The Geometry of the frequency reconfigurable filtenna and the simulated and measured $S$ parameter results when the filtenna is in wide band are shown in Figure 3. The measured results show that when the filtenna is working in wide band state, the bandwidth is $2.63 \mathrm{GHz}$ (from $2.35 \mathrm{GHz}$ to $4.98 \mathrm{GHz}$ ) and when the filtenna is in narrow band state, the bandwidth is 1.34 $\mathrm{GHz}$ (from $3.05 \mathrm{GHz}$ to $4.39 \mathrm{GHz}$ ).Another reconfigurable, compact 4 element multiple input multiple output antenna with a pentagonal slot presented in [20]. This antenna is capable of operating in the band $3.230 \mathrm{GHz}$ to $3.880 \mathrm{GHz}$. Reconfigurability is attained using varactor diodes by the capacitance varying of pentagonal slot antenna. This design is best suited for WiMAX bands and cognitive radio applications. 


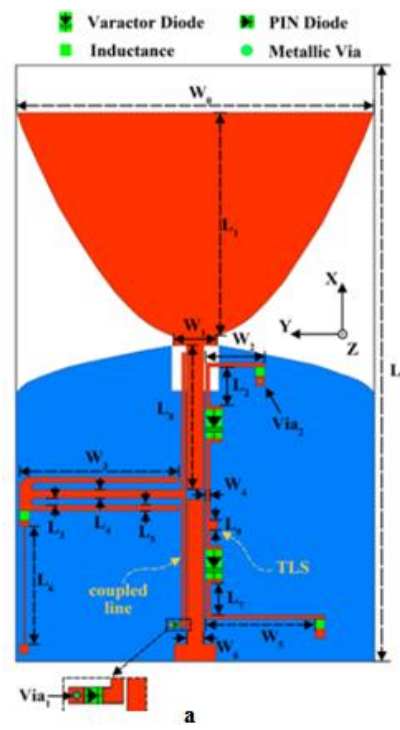

(a)

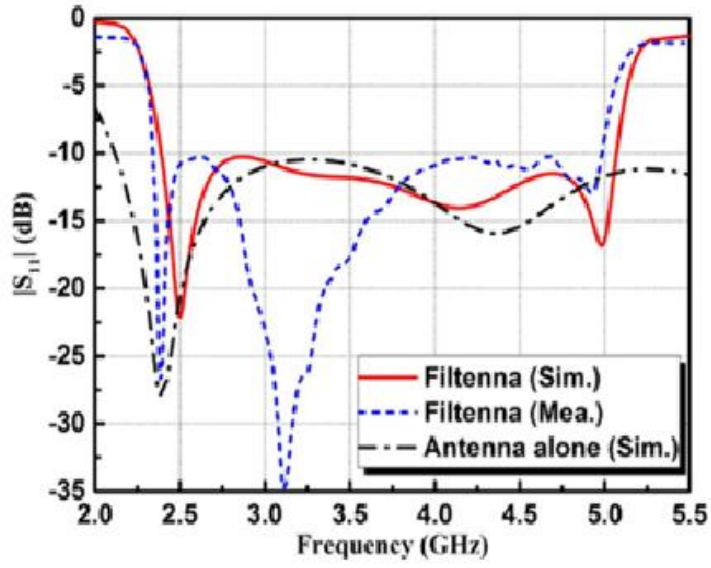

(b)

Figure 3. (a) Geometry of the filtenna (b) Simulated and measured S parameter results when the filtenna is in wide band state

\subsection{Optically reconfigurable antennas}

It reports an optically reconfigurable antenna for cognitive radio applications in [22]. This design is composed of an ultrawideband unit to sense the frequency spectrum from $2.5 \mathrm{GHz}$ to $8 \mathrm{GHz}$, and a reconfigurable unit which is able to switch between the frequencies $3.9 \mathrm{GHz}$ and $6.2 \mathrm{GHz}$. Reconfigurability could be obtained using optical switches, namely Si. Figure 4 shows the optically switched transmission line that is fabricated using Taconic substrate and the prototype of the antenna. A rectangular block of Si is used to vary the length of the ground plane of the antenna. The dark and active states of the reconfigurable unit are controlled using $880 \mathrm{~nm}$ infrared emitting diodes. For dark and active states, the operating frequency of the reconfigurable antenna lies within the band of operation of the ultrawideband sensing unit, hence provides the functionality of a cognitive radio. The gain of the reconfigurable antenna is higher for dark state than for active state as in the active state, there is power loss in the reconfigurable antenna due to the increase of losses of $\mathrm{Si}$ switch. Another optically reconfigurable notched ultrawideband antenna for cognitive radio systems is presented [23]. A folded slot is inserted on a $U$ shaped ultrawideband antenna. The various setup positions and the 'ON' or 'OFF' combination of photoconductive switches make the antenna to achieve the rejection characteristics. This structure is operated in a wide band with switchable band rejection in wireless local area network (WLAN) $2.4 \mathrm{GHz}(2.2-2.9 \mathrm{GHz})$, worldwide interoperability for microwave access (WiMAX) (3.24.7 GHz), WLAN $5 \mathrm{GHz}(4.8-6.6 \mathrm{GHz})$ and the ITU $8 \mathrm{GHz}(7.5-8.7 \mathrm{GHz})$.

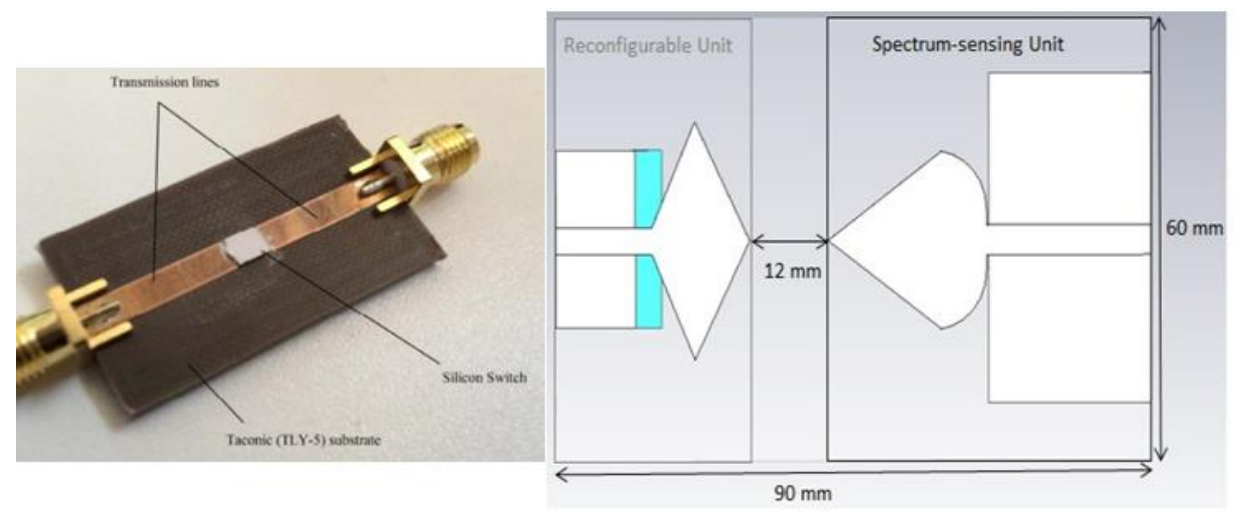

(a)

(b)

Figure 4. (a) Optically switched microstrip transmission line (b) Prototype of the optically switched cognitive radio system 


\subsection{Physically reconfigurable antennas}

Physically Reconfigurable antennas for Cognitive Radios consist of a sensing antenna and a frequency reconfigurable antenna. The sensing antenna will be an ultra wideband antenna, that scans the frequency spectrum to discover unused bands whereas the reconfigurable antenna is tuned to communicate in these bands. In physically reconfigurable antennas, a rotational motion of the radiating patch is needed for the working.

An antenna system is presented for cognitive radio applications where reconfigurable antenna is composed of five patches and the operable range varies from $2.3 \mathrm{GHz}$ to $10.6 \mathrm{GHz}$ [27]. Each patch is operated at different frequencies bands. The rotation is regulated by a stepping motor placed at the back of the antenna. This antenna is capable of scanning the spectrum from $1.7 \mathrm{GHz}$ to $10.6 \mathrm{GHz}$. The structure of the antenna and the return loss of the reconfigurable antenna at different shapes obtained by rotating the patch are depicted in Figure 5. The bands covered by shapes $1,2,3,4$ and 5 are $2.3-4.5 \mathrm{GHz}, 3.8-5 \mathrm{GHz}, 4.8-7.4 \mathrm{GHz}$, 6.3-8.2 GHz and 8-10.6 GHz respectively.Another antenna design consists of an ultrawideband antenna and a frequency reconfigurable antenna used for cognitive radios is reported in [28]. In this case, the rotational motion of motor is controlled by LABVIEW on a computer connected to the motor through its parallel port.

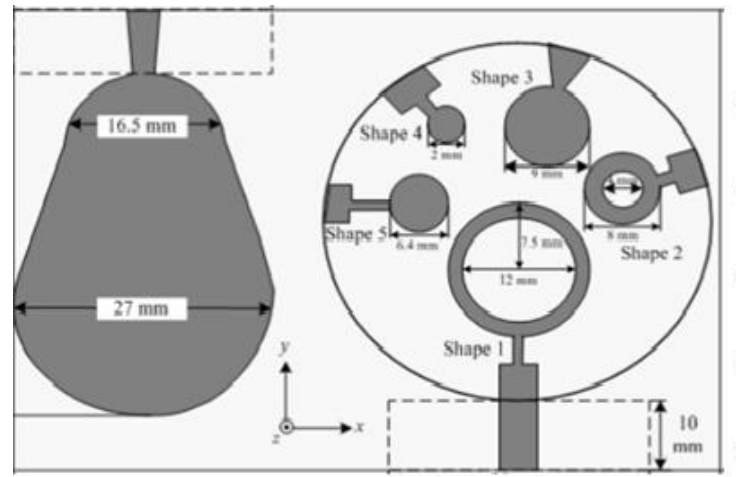

(a)

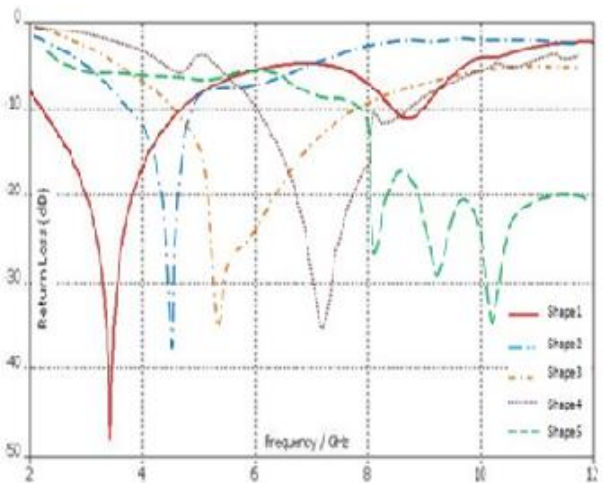

(b)

Figure 5. (a) The Antenna Structure (b) Return Loss plot of the Reconfigurable Antenna

\subsection{Reconfigurable antennas based on smart materials}

A compact reconfigurable wearable antenna implemented on a fabric substrate is presented [33]. It can operate on bands, such as ISM, Wi-Fi and Wi-Max in ultrawideband frequency range. Along with, this antenna provides radiation pattern reconfiguration. To construct the metal part of antenna, the materials used for the substrate are cotton and leather, combined with fabric copper or conducting thread embroidery. Five prototypes are considered in this case as Antenna 1 to Antenna 5. The substrate and conductive path of Antenna 1 to Antenna 5 are Cotton Denim $\left(\varepsilon_{\mathrm{r}}=1.2\right)$ and Conductive Sewing Thread, Cotton Calico $\left(\varepsilon_{\mathrm{r}}=1.2\right)$ and Conductive Sewing Thread, Cotton Denim and Copper Fabric, Cotton Calico and Copper Fabric and Leather $\left(\varepsilon_{\mathrm{r}}=2.3\right)$ and Copper Fabric respectively. The prototype of the antenna on leather and the measured return loss of antennas at ultrawideband configuration is depicted in Figure 6. Stubs of different lengths are responsible for reconfiguration in this antenna and when all the switches are OFF, the antenna is well suited for cognitive radio with operable band 3 to $8 \mathrm{GHz}$.

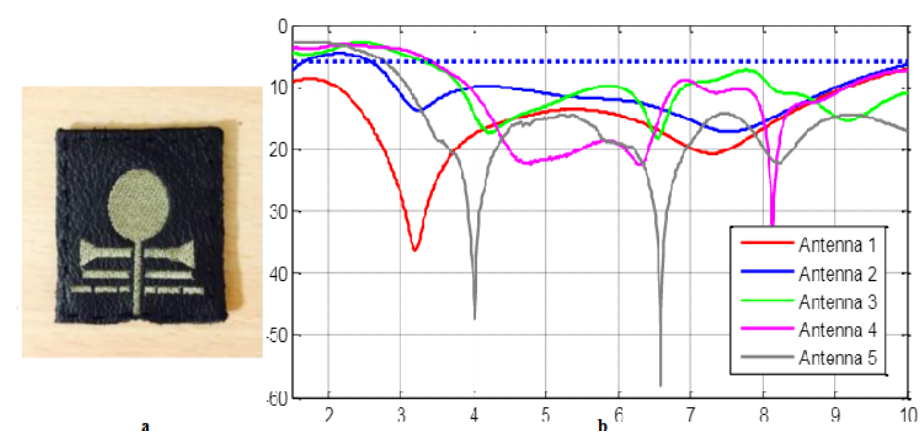

Figure 6. (a) Prototype of the antenna on leather (b) Measured return loss of antennas 


\section{RESULTS AND DISCUSSION}

The Reconfiguration techniques reviewed so far, Electrical, Optical, Physical and Smart material usage to achieve Frequency Reconfiguration for Cognitive Radios can be compared according to their performance in terms of switching speed, isolation, power requirements, losses, reliability, etc. The advantages and disadvantages of these techniques are consolidated and summarized below.

Electrical reconfiguration has been found as the most prominent methodology for achieving the frequency reconfiguration. RF MEMS switches are more reliable and are best suited for working in the millimeter wave and microwave range frequencies such as phase shifters, software defined radio, reconfigurable antennas, tunable band pass filters, resonators, etc. [9-10]. MEMS switches provide fast switching operation, linearity, isolation, better adaptation and lower signal distortion [11-12]. The insertion loss is very low of the order $0.16 \mathrm{~dB}$ and Quality factor is very high up to frequencies of $120 \mathrm{GHz}$. The switching loss is very less, and they can be controlled using 10 to $120 \mathrm{~K}$ resistive lines. The bias network of RF MEMS switches will not degrade antenna radiation pattern but power handling capabilities of RF MEMS switches are less [13]. Adversely, high voltage is needed for activation of RF-MEMS switches [14].

PIN diodes can be used for switching between bands while varactor diodes can be utilized for smooth variation of the resonating frequencies. The fine tuning of the varactor is more noticeable in the lower frequency bands $[15,17]$. The responses of PIN diodes and varactors are faster and are of the order of nanoseconds. These switches make the reconfigurable antennas more scalable. These switches can be easily incorporated in the antenna structure. But these are nonlinear in nature. For PIN diodes the insertion loss is $0.4 \mathrm{~dB}$ to $0.7 \mathrm{~dB}$ [18]. High voltage is needed by varactors for activation [21].

Electronic switches need biased voltage lines to activate them, which will distort the radiations of the antenna in most of the designs. Additionally, mechanical switches are complicated to manufacture and are likely to be heavy, restricting flexibility of design. Whereas optical switches offer immunity from such electromagnetic interferences as the isolation is quite high in between the controlling and radiating signals of the antenna. Also, they are of lightweight, having high switching speed and can be easily fabricated [22, 24-25]. Laser diodes can directly be integrated into the antenna structure. Hence, optical fiber cables do not need directing light to the photoconductive switches. Thus, the complexity of the system is reduced and these antennas can be easily integrated in the upcoming wireless handheld devices. No bias lines are needed in this case for the activation of switches as in the cases of RF MEMS and PIN diodes [26].

In Physically reconfigurable antennas, bias lines, laser diodes or optical fibers are not needed for the activation of switches. The constraints of this technique are cost, size, power source requirements, etc. The designing is complicated as it involves incorporation of reconfiguring element into the antenna structure. These designs provide slower responses comparing to others [27-32].

The idea of wearable devices evolved with the hasty growth in the usage of communication devices. And it can be realized using reconfiguration technique with smart materials. If the antenna is embedded, lightweight, compact, and wearable, it can be part of daily clothing and will be sufficient for on body wireless communication. The applications lie in the areas of navigation, mobile computing, health care, tracking, public safety, and military [33].

\section{CONCLUSION}

Cognitive Radios have been considered as the emerging technology which can fill the gaps in the efficient usage of RF spectrum. The Cognitive radios are found to follow an algorithm of 'sensing of spectrum' to find the unused frequency bands in the range of sensing antenna, 'deciding on spectrum' to find the apt band for communication and 'controlling of switches or methods' to tune resonant frequencies of Frequency Reconfigurable Antennas. Frequency Reconfigurable Antennas, the major constituent of Cognitive Radios has been surveyed detailed on basis of different reconfiguration techniques in this paper. The four techniques to achieve reconfiguration can be enlisted as electrical, optical, physical, and smart material based. A number of antennas designed with each of these techniques are studied to perform a comparative study on basis of different parameters such as switching speed, isolation, power requirements, losses, reliability, etc. The advantages and disadvantages of the techniques are detailed in this paper in order to decide the best method according to the constraints of the antenna designers in the field of Academics and Industry.

\section{ACKNOWLEDGEMENTS}

The authors would like to thank the Department of Electronics and Communication Engineering of Sahrdaya College of Engineering \& Technology, Kodakara, Kerala, India for the help and support extended for carrying out this work. 


\section{REFERENCES}

[1] Q. Zhao and B. M. Sadler, "A Survey of Dynamic Spectrum Access," in IEEE Signal Processing Magazine, vol/issue: 24(3), pp. 79-89, May 2007.

[2] Federal Communications Commission, "Report of the spectrum efficiency working group," FCC spectrum policy task force, Technical Report, 2002.

[3] K. L. A. Yau, et al., "A context-aware and Intelligent Dynamic Channel Selection scheme for cognitive radio networks," 2009 4th International Conference on Cognitive Radio Oriented Wireless Networks and Communications, Hannover, pp. 1-6, 2009.

[4] G. Srivastava, et al., "Compact Reconfigurable UWB Slot Antenna for Cognitive Radio Applications," IEEE Antennas and Wireless Propagation Letters, vol. 16, pp. 1139-1142, 2017.

[5] R. Hussain, et al., "An Integrated Four-Element Slot-Based MIMO and a UWB Sensing Antenna System for CR Platforms," IEEE Transactions on Antennas and Propagation, vol/issue: 66(2), pp. 978-983, Feb 2018.

[6] L. Ge, et al., "Unidirectional Dual-Band Stacked Patch Antenna with Independent Frequency Reconfiguration," IEEE Antennas and Wireless Propagation Letters, vol. 16, pp. 113-116, 2017.

[7] Y. Cai, et al., "A Low-Profile Frequency Reconfigurable Grid-Slotted Patch Antenna," IEEE Access, vol. 6, pp. 36305-36312, 2018.

[8] C. B. Fortuny, et al., "Low-cost mechanism to reconfigure the operating frequency band of a Vivaldi antenna for cognitive radio and spectrum monitoring applications," IET Microwaves, Antennas \& Propagation, vol/issue: 12(5), pp. 779-782, 2018.

[9] A. A. Ibrahim, et al., "Design of reconfigurable antenna using RF MEMS switch for cognitive radio applications," 2017 Progress in Electromagnetics Research Symposium - Spring (PIERS), St. Petersburg, pp. 369-376, 2017.

[10] Abirami M. and Rajasekar G., "MEMS reconfigurable slotted microstrip patch antenna for cognitive radio application," 2016 Online International Conference on Green Engineering and Technologies (IC-GET), Coimbatore, pp. 1-4, 2016.

[11] R. George, et al., "Design of a frequency reconfigurable pixel patch antenna for cognitive radio applications," 2016 International Conference on Communication and Signal Processing, Melmaruvathur, pp. 1684-1688, 2016.

[12] T. Wu, et al., "Switchable Quad-Band Antennas for Cognitive Radio Base Station Applications," in IEEE Transactions on Antennas and Propagation, vol/issue: 58(5), pp. 1468-1476, May 2010.

[13] S. Arivazhagan, et al., "Design of a reconfigurable antenna for cognitive radio," 2015 IEEE International Conference on Electrical, Computer and Communication Technologies (ICECCT), Coimbatore, pp. 1-5, 2015.

[14] H. Rajagopalan, et al., "MEMS Reconfigurable Optimized E-Shaped Patch Antenna Design for Cognitive Radio," in IEEE Transactions on Antennas and Propagation, vol/issue: 62(3), pp. 1056-1064, Mar 2014.

[15] R. Hussain and M. S. Sharawi, "Planar meandered-F-shaped 4-element reconfigurable multiple-input-multipleoutput antenna system with isolation enhancement for cognitive radio platforms," in IET Microwaves, Antennas \& Propagation, vol/issue: 10(1), pp. 45-52, 2016.

[16] P. Y. Qin, et al., "A Wideband-to-Narrowband Tunable Antenna Using a Reconfigurable Filter," in IEEE Transactions on Antennas and Propagation, vol/issue: 63(5), pp. 2282-2285, May 2015.

[17] R. Hussain and M. S. Sharawi, "4-element planar MIMO reconfigurable antenna system for cognitive radio applications," 2015 IEEE International Symposium on Antennas and Propagation \& USNC/URSI National Radio Science Meeting, Vancouver, BC, pp. 717-718, 2015.

[18] M. Ali, et al., "A Reconfigurable Stacked Microstrip Patch Antenna for Satellite and Terrestrial Links," in IEEE Transactions on Vehicular Technology, vol/issue: 56(2), pp. 426-435, Mar 2007.

[19] M. C. Tang, et al., "Compact, Frequency-Reconfigurable Filtenna with Sharply Defined Wideband and Continuously Tunable Narrowband States," in IEEE Transactions on Antennas and Propagation, vol/issue: 65(10), pp. 5026-5034, Oct 2017.

[20] R. Hussain and M. S. Sharawi, "Reconfigurable pentagonal slot based 4-element MIMO antennas," 2017 IEEE International Symposium on Antennas and Propagation \& USNC/URSI National Radio Science Meeting, San Diego, CA, pp. 1151-1152, 2017.

[21] L. Ge, et al., "Unidirectional Dual-Band Stacked Patch Antenna with Independent Frequency Reconfiguration," in IEEE Antennas and Wireless Propagation Letters, vol. 16, pp. 113-116, 2017.

[22] A. Andy, et al., "An optically-switched frequency reconfigurable antenna for cognitive radio applications," 2016 10th European Conference on Antennas and Propagation (EuCAP), Davos, pp. 1-4, 2016.

[23] S. H. Zheng, et al., "Optically controlled reconfigurable band-notched UWB antenna for cognitive radio systems," in Electronics Letters, vol/issue: 50(21), pp. 1502-1504, Oct 2014.

[24] D. Zhao, et al., "Optically Controlled Reconfigurable Band-Notched UWB Antenna for Cognitive Radio Applications," in IEEE Photonics Technology Letters, vol/issue: 26(21), pp. 2173-2176, Nov 2014.

[25] G. P. Jin, et al., "Optically controlled reconfigurable antenna for cognitive radio applications," in Electronics Letters, vol/issue: 47(17), pp. 948-950, Aug 2011.

[26] Y. Tawk, et al., "Demonstration of a Cognitive Radio Front End Using an Optically Pumped Reconfigurable Antenna System (OPRAS)," in IEEE Transactions on Antennas and Propagation, vol/issue: 60(2), pp. 1075-1083, Feb 2012.

[27] P. Tummas, et al., "A frequency reconfigurable antenna design for UWB applications," 2014 11th International Conference on Electrical Engineering/Electronics, Computer, Telecommunications and Information Technology (ECTI-CON), Nakhon Ratchasima, pp. 1-4, 2014. 
[28] Y. Tawk, et al., "Implementation of a Cognitive Radio Front-End Using Rotatable Controlled Reconfigurable Antennas," in IEEE Transactions on Antennas and Propagation, vol/issue: 59(5), pp. 1773-1778, May 2011.

[29] Y. Tawk, et al., "A rotatable reconfigurable antenna for cognitive radio applications," 2011 IEEE Radio and Wireless Symposium, Phoenix, AZ, pp. 158-161, 2011.

[30] Y. Tawk, et al., "A frequency reconfigurable rotatable microstrip antenna design," 2010 IEEE Antennas and Propagation Society International Symposium, Toronto, ON, pp. 1-4, 2010.

[31] Y. Tawk and C. G. Christodoulou, "A New Reconfigurable Antenna Design for Cognitive Radio," in IEEE Antennas and Wireless Propagation Letters, vol. 8, pp. 1378-1381, 2009.

[32] Y. Tawk and C. G. Christodoulou, "A cellular automata reconfigurable microstrip antenna design," 2009 IEEE Antennas and Propagation Society International Symposium, Charleston, SC, pp. 1-4, 2009.

[33] A. da C. Andrade, et al., "Reconfigurable textile-based ultra-wideband antenna for wearable applications," 2016 10th European Conference on Antennas and Propagation (EuCAP), Davos, pp. 1-4, 2016.

\section{BIOGRAPHIES OF AUTHORS}
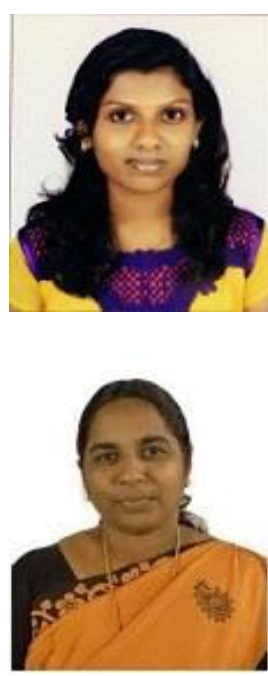

Ros Marie C Cleetus received the B.Tech. degree in Electronics \& Communication engineering from Mahatma Gandhi University, India, in 2010, the M.Tech. degree in Communication Engineering from University of Calicut, India, in 2013. She is currently a Research Scholar at Department of Electronics \& Communication Engineering, Karunya Institute of Technology and Sciences, India. She is working as an Assistant Professor in the Department of Electronics \& Communication Engineering at Sahrdaya College of Engineering \& Technology, India. Her research interests include Wireless Communication, Reconfigurable Antennas, and Cognitive Radio.

G. Josemin Bala received her Bachelor's degree in Engineering from Bharathidasan University, India, in 1996, the Master's degree in Engineering from REC, Trichy, India, in 1999 and received her $\mathrm{PhD}$ degree from Anna University, India in 2008. Currently she is working as Professor in the Department of Electronics \& Communication Engineering, Karunya Institute of Technology and Sciences, India. Her research interests include Communication Networks and RF Systems. She has published a number of conference proceedings and papers in National and International journals. Recently in 2017, she received the "Outstanding Women Educator \& Scholar Award" from National Foundation for Entrepreneurship Development for her contributions and achievements in the field of Engineering. 